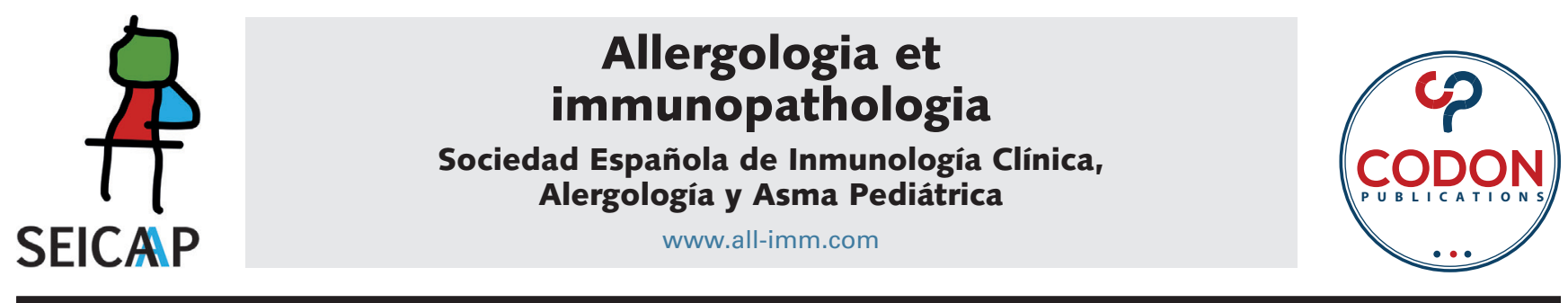

EDITORIAL

\title{
Response to the letter of Dr. Helmi Ben Saad
}

\section{Javier Mallol (on behalf of all co-authors)}

Professor of Pediatrics, Dept. of Pediatric Respiratory Medicine

Hospital CRS El Pino, University of Santiago de Chile, Santiago, Chile

Received 25 January 2021; Accepted 28 January 2021

Available online 1 March 2021

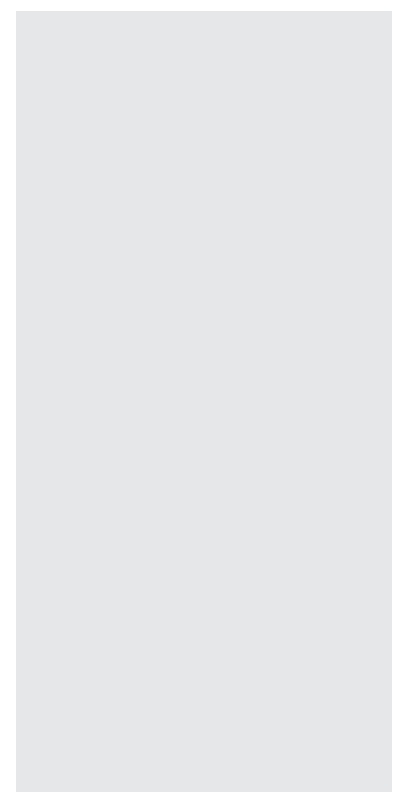

We thank Dr. Saad for his valuable comments on our article ${ }^{1}$ and his agreement with the main conclusion of this real-life study in asthmatic children; the message for clinicians at daily clinical work is that common "asthma tests" perform poorly in corroborating the diagnosis of asthma in children. Therefore, the diagnosis of asthma and the decision to begin the appropriate asthma treatment should be mainly relayed on a careful anamnesis and physical examination also considering the clinical evolution and treatment response. Dr. Been provides us with a useful complementary analysis with emphasis on an intensively debatable matter as to what is a BDR, ${ }^{2,3}$ particularly in children. He shows there are several different possible responses to that question, as recommended by different guidelines and consensus. The ATS-ERS 2005 and 2019 guidelines ${ }^{4,5}$ gives the chance of using "FEV1 (or FVC)"; we chose FEV1 for the assessment of BDR in our children"; however, we think that any selection from the table in the letter of Dr. Been may be susceptible to debate. In children, the situation could be worst as the information and the parameters employed to define a positive BDR, whatever be the test or cutoff employed, are far to find a consensus, and even less, to be based on a robust body of evidence.

In our study, bronchodilator response, FENO, and spirometry values (but not methacholine test) showed poor performance for corroborating the diagnosis of asthma but they are probably useful for assessing other aspects of the management and follow-up of asthmatic children. While better evidence is available, clinical criteria should prevail to corroborate the diagnosis of asthma and initiate the corresponding asthma treatment in pediatric patients.

\footnotetext{
*Corresponding authors: Prof. Javier Mallol (on behalf of all co-authors), Professor of Pediatrics, Dept. of Pediatric Respiratory Medicine, Hospital CRS El Pino, University of Santiago de Chile, Santiago, Chile. E-mail Address: Javier.mallol@usach.cl
} 


\section{References}

1. Mallol J, Riquelme C, Aguirre V, Martínez M, Gallardo A, Sánchez $C$, et al. Value of bronchial reversibility to salbutamol, exhaled nitric oxide and responsiveness to methacholine to corroborate the diagnosis of asthma in children. Allergol Immunopathol (Madr). 2020 May-Jun;48(3):214-22. https://doi. org/10.1016/j.aller.2019.11.001

2. Been Saad H. Letter to Editor, it's high time for the scholarly societies to standardize the bronchodilator responsiveness in children. Allergol Immunopathol (Madr), 2021. https://doi. org/10.1002/ppul.25234

3. Guezguez F, Ben Saad H. What constitutes a "clinically significant" bronchodilator response in children? Eur Respir J. 2020;55(5):2000207. https://doi.org/10.1183/13993003.00207-2020

4. Pellegrino R, Viegi G, Brusasco V, Crapo RO, Burgos F, Casaburi R, et al. Interpretative strategies for lung function tests. Eur Respir J. 2005;26:948-68. https://doi.org/10.1183/09 031936.05.00035205

5. Graham BL, Steenbruggen I, Miller MR, Barjaktarevic IZ, Cooper BG, Hall GL, et al. Standardization of spirometry 2019 update. An Official American Thoracic Society and European Respiratory Society Technical Statement. Am J Respir Crit Care Med. 2019 Oct 15;200(8):e70-88. https://doi.org/10.1164/ rccm.201908-1590ST 